\title{
Kobalt(II)'nin Amberlit XAD-4/SCHD Reçinesi Kullanılarak Yeni bir Katı-Faz Ekstraksiyon Yöntemi ile Zenginleştirilmesi ve Spektrofotometrik Tayini
}

\author{
Preconcentration of Co(II) by a New Solid-PhaseExtraction Method using Amberlite XAD- \\ 4/SCHD Resin and Spectrophotometric Determination
}

\author{
Berrin TOPUZ*,a ${ }^{*}$ Nazlı BALDAN PAKDİL ${ }^{\mathrm{b}}$, Aysel SOLMAZ \\ Abant İzzet Baysal Üniversitesi, Mühendislik Mimarlık Fakültesi, Çevre Mühendisliği Bölümü, 14030, Bolu
}

• Geliș tarihi / Received: 07.12.2017 • Düzeltilerek geliş tarihi / Received in revised form: 27.04.2018 • Kabul tarihi / Accepted: 15.05 .2018

\begin{abstract}
$\ddot{O} z$
$\mathrm{Bu}$ çalışmada, çevresel su numunelerinden eser miktardaki Co(II)'nin, Amberlit XAD-4-N,N-bis(salisilidin)siklohegzandiamin (SCHD) reçinesi kullanılarak katı faz ekstraksiyon yöntemiile ön deriștirilmesi, ayrılması ve UVVIS spektrofotometrik yöntemle tayini için yeni bir metot önerilmiştir. Bu amaçla, Co(II) için XAD-4-SCHD reçinesi ile sorpsiyon ve elüsyon parametreleri $(\mathrm{pH}$, elüent tipi ve konsantrasyonu, elüent hacmi, maksimum numune hacmi, numune akış hızı, elüent akış hızı) incelenmiştir. Box Behnken Dizayn Programı kullanılarak katı faz ekstraksiyonu ile Co(II)'nin geri kazanımı için sorpsiyon ve elüsyon bağımsız değişkenleri optimize edilmiştir. Önerilen yöntemin kalibrasyon grafiğginin $0.06-3 \mu \mathrm{gmL}^{-1}$ aralığında doğrusal olduğu tespit edilmiştir $\left(\mathrm{r}^{2}=0.9980\right)$. Önderiştirme faktörü ve gözlenebilme sınırı sırasıyla 100 ve $8.4 \mu \mathrm{gL}^{-1}$, dir. Yöntemin doğruluğu, sertifikalı standart su numunesinin (NWTMDA-70.2) analizi ile kontrol edilerek \% 90'ın üzerinde geri kazanım değerleri elde edilmiştir. Ayrıca, bu çalışmada önerilen metot kullanılarak eser miktarda $\mathrm{Co}$ (II) içeren farklı çevresel su numunelerinden elde edilen ölçüm sonuçları, ICP-MS ölçüm sonuçları ile benzer bulunmuştur. Önerilen metot, çevresel su numunelerinde eser miktardaki Co(II)'nin tayini için başarıyla uygulanmıştır.
\end{abstract}

Anahtar kelimeler: Amberlit XAD-4/SCHD reçinesi, Box-behnken dizayn, Co(II), Katı-faz ekstraksiyonu, UV-VIS spektrofotometri

\begin{abstract}
The study presents a novel method for the separation/enrichmentand UV-VIS spectrophotometric determination of traceCo(II) from environmental water samples using Amberlite XAD-4 resin modified with N,N-bis(salisilidin)siklohegzandiamin (SCHD). For this aim, sorption and elütion parameters of Co(II) (pH, eluent type and concentration, eluent volume, maximum sample volume, sample flow rate, eluent flow rate) with XAD-4-SCHD resin were investigated. Sorption and elution independent variables were optimized using Box Behnken Design (BBD) program for there covery of $\mathrm{Co}(\mathrm{II})$ by solid phase extraction. Calibration graph was linear in the range of 0.06$3 \mu g m L^{-1}\left(r^{2}=0.9980\right)$. Preconcentration factor and dedection limit of the proposed methods were100 and $8,4 \mu g L^{-1}$, respectively. The accuracy of the method was checked by analysis of the certified standard water sample (NW-TMDA70.2), and recovery values above 90\% were obtained. In addition, using the proposed method in this study, the measurement results obtained from different environmental water samples containing trace amounts of Co(II) were found to be similar to the ICP-MS measurement results. The proposed method was successfully applied for the determination of trace amount of $\mathrm{Co}(\mathrm{II})$ in environmentalwatersamples.
\end{abstract}

Keywords: Amberlite XAD-4/SCHD resin, Box-behnken design, Co(II), Solid phaseextraction, UV-VIS spectrophotometry

\footnotetext{
*a Berrin TOPUZ; berrintopuz@ibu.edu.tr; Tel: (0374) 2541000 (dahili: 4909); orcid.org/0000-0002-0374-3921

${ }^{\mathrm{b}}$ orcid.org/0000-0003-2279-0405 $\quad{ }^{\mathrm{c}}$ orcid.org/0000-0002-8654-3887
} 


\section{Giriş}

Vücudumuzdaki yaşamsal faaliyetler için gerekli B12 vitamininin yapıtaşı olan kobalt, ayrıca kan hücrelerinden biri olan eritrosit oluşumunda da önemli bir elementtir. Bu nedenle vücutta kobalt eksikliği durumunda "pernisyöz anemi" denilen kansızlık hastalığı, karaciğer, pankreas ve sinir sisteminde bozukluk gibi pek çok problemler ve semptomlar ortaya çıkar. Ancak aşırı kobalt alımı da, kobalt zehirlenmelerine yol açar.

Kobalt stratejik ve endüstriyel uygulamalarda ve askeri alanda önemli kullanım alanlarına sahiptir. Özellikle cam, porselen, seramik, boya v.b. yapımında kullanılmaktadır. Farklı sanayi kollarının atıksularının nehirlere verilmesi ve sulama suyu olarak tarlalarda kullanılması toprak, sediment ve sudaki kobalt konsantrasyonlarının artışına önemli ölçüde katkı sağlamaktadır. Birleşik Devletler Çevre Koruma Ajansı (United States of Environmental Protection Agency (USEPA)), tarafından içme sularında izin verilebilir maksimum kobalt miktarı $100 \mu \mathrm{gL}^{-1}$ olarak belirtilmiştir. Bu nedenle sularda doğru ve hassas kobalt tayininin yapılmas1 önemlidir (Jamali vd., 2017).

Sularda kobalt tayini için, indüktif eşleşmiş plazma-kütle spektrometri (ICP-MS), indüktif eşleşmiş plazma-opti kemisyon spektrometri (ICP-OES) ve atomik absorpsiyon spektrometri (AAS) gibi hassas ve seçici modern enstrümental teknikler kullanılabilmesine rağmen çok kompleks numune matriksi içerisindedüşük miktarlardaki metal seviyelerinin analizinde zorluklar halen devam etmektedir. Bu yüzden, matriks etkisi ve kirliliklerin ayrılması, farklı modern enstrümental tekniklerle tayin edilemeyen düşük tayin sınırındaki eser elementlerin analizi içintayin öncesi uygun ayırma ve önderiştirme yöntemleri gerekmektedir (Camel, 2003). Bu amaçla sıv1 sıvı mikroekstraksiyonu (LLME) (Baliza, 2009), bulutlanma noktası ekstraksiyonu (CPE) (Citak ve Tüzen, 2010), birlikte çöktürme (Soylak vd., 2007), ve kat1-siv1 ekstraksiyonu (SPE) (Safavi, 2006) gibi yöntemler uygulanmaktadır. Ancak SPE yönteminin, çevreye zararlı organik çözücülerin kullanılmaması, yüksek numune hacmi ile çalışılarak önderiştirme faktörünün yüksek elde edilebilmesi, kullanılan katı fazın tekrar tekrar kullanılabilmesi gibi avantajları vardır.SPE yönteminde karbonnanotüp (Wang vd., 2016), magnetik iyon yüklü polimerler (Khoddami ve Shemirani, 2016), silikagel (Sivrikaya vd., 2016), Amberlite XAD reçineleri (Alpdoğan, 2016) gibi farklı katı fazlar Co(II) tayininde kullanılmaktadır. Amberlit XAD kopolimerlerinin, eser metal iyonlarının zenginleştirilmesinde, yüksek saflıkları, dayanıklılık, homojen por dağılımı, yüksek yüzey alanı gibi iyi sorpsiyon özellikleri nedeni ile diğer sorbentlere oranla daha geniş bir uygulama alanı vardır. Gözenek büyüklüğü ve yüzey alanı arasında ters bir ilişki vardır. Gözenek büyüklüğü küçüldükçe yüzey alan büyür. Amberlite XAD reçineleri için bu özellikler incelendiğinde XAD-4 reçinesi XAD-2, XAD-2000, XAD-7, XAD-1180, reçinelerine göre daha yüksek yüzey alanına sahiptir. Çalışmamızda yüksek yüzey alanına sahip Amberlite XAD-4 reçinesi, azot ve oksijen donör atomu içeren ve $\mathrm{Cu}(\mathrm{II}), \mathrm{Ni}(\mathrm{II}), \mathrm{Pb}(\mathrm{II})$, $\mathrm{Zn}(\mathrm{II}) \mathrm{Co}(\mathrm{II}), \mathrm{Mn}(\mathrm{II})$ ve $\mathrm{Cd}(\mathrm{II})$ iyonları için yüksek seçicilik özellik gösteren N,N bis(salisilidin)siklohegzandiamin (SCHD) schiff bazı ile modifiye edilerek (Topuz ve Macit, 2011) Co(II) iyonunu su numunelerinden ayrilması ve önderiştirilmesi amacıyla kullanılmıştır.

Ditiyokarbamat (DTC) bileşikleri, içerdikleri iki adet elektron çifti vericisi kükürt atomu sayesinde birçok metalle formülü $\mathrm{M}(\mathrm{DTC}) \mathrm{n}$ olan kararlı koordinasyon bileşikleri oluştururlar (Topuz, 2004). Metal ditiyokarbamat kompleksleri yüksek absorbans kapasitesine sahip olduklarından dolay genellikle UV-VIS spektrofotometresi ile ölçülebilmektedir. Bakır, nikel, kobalt, mangan gibi metallere karşı yüksek metal bağlayıcılık kapasitesi olan DTC bileşikleri, metal iyonları ile renkli kompleksler vermektedir. Farklı metallerle DTC bileşiklerinin özgün renk oluşumunun sağlanmas1, UV-VIS Spektrofotometrik ölçümlerde metal iyonuna karşı seçici analizlerde önemli avantajdır.

Önderiştirmeyle ilgili çalışmaların çoğunda metal iyonları, değişkenlerin bir tanesi kullanılarak optimize edilir. Böyle bir optimizasyon sürecinde, diğer değişkenlerin etkileşimleri dikkate alınmaz ve elde edilen cevap tek bir değişkenin geri kazanım üzerine etkisini gösterir. Öte yandan deneysel tasarım, değişkenlerin birbiriyle ilişkisini de ortaya koymaktadır. Box Behnken Dizayn Programı ikinci dereceden bir polinom modelinin inşa edilmesi ve değişkenlerin ilişkilerini matematiksel olarak gösterir.

$\mathrm{Bu}$ çalı̧̧mada, N,N bis(salisilidin)siklohegzandiamin (SCHD) ile modifiye edilen Amberlit XAD-4 reçinesiyle Co(II) iyonunun önderiştirilme ve ayrılması için geliştirilen SPE yöntem parametrelerinin deneysel verileri, Box-Behnken Yanıt Yüzey Yöntemi kullanılarak sabit fazın sorpsiyon ve elüsyon kapasitesini maksimize eden 
optimum SPE şartları belirlenerek bağımsız ve bağımlı değişkenler arasındaki matematiksel ilişki net bir şekilde ifade edilmiştir. Önderiştirilen ve ayrılan Co(II) iyonunun UV-VIS spektrofotometrik tayini için sentezlenen 2,6 dimetilmorfolinditiyokarbamat (DMMDTC) reaktifi kullanılmıştır.

\section{Deneysel Çalışmalar}

\subsection{Kullanulan Cihazlar}

Bu çalışmada Co(II) tayini için $1 \mathrm{~cm}$ kuvarz küvet ile UV-VIS spektrofotometre (Spektroquant Pharo 300 Merck) kullanılmıştır. Co(II) iyonunun yeşil renkli DMMDTC kompleksinin dalga boyu $342 \mathrm{~nm}$ olarak belirlenmiştir. $\mathrm{pH}$ ölçümleri ISOLAB dijital $\mathrm{pH}$-metre ile gerçekleştirilmiştir. Tartımlar RADWAG marka analitik terazi (0.00001 duyarl1l1kta) ile gerçekleştirilmiştir. Çevresel su numunelerinin süzülmesi işleminde $0.45 \mu \mathrm{m}$ gözenekli (MerckMillipore) selüloz membran filtre kağıdı kullanılmıştır. Önderiştirme çalışmalarında $10 \mathrm{~cm}$ uzunluğunda $1 \mathrm{~cm}$ iç çapında bir mini cam kolon ile BLUPUMP marka AKM pompas1 kullanılmıştır. Batch yöntemi çalışmalarında MEDİSPEC marka roller karıştırıcı kullanılmıştır. Ayrıca önerilen yöntemin analiz sonuçlarını karşılaştırmak için PerkinElmerSCIEX ELAN DRCe ICP-MS cihazı kullanılmıştır.

\subsection{Kullanılan Reaktifler ve Standart Çözeltiler}

Co(II) iyonunun kat1-sıv1 ekstraksiyon tekniği ile önderiştirilmesi ve çözelti ortamından ayrılmasında, daha önce gerçekleştirilen bir çalışmada sentezlenenAmberlit XAD-4-SCHD (Şekil 1) reçinesi kullanılmıştır (Topuz 2011). Yöntemin doğruluğunun belirlenmesi amacıyla bir sertifikalı referans madde (NW-TMDA-70.2, Environmental Matrix Reference Material Canada) kullanılmıştır.

ÖnderiştirilenCo(II) iyonlarının UV-VIS spektrofotometrik tayini için, daha önceden belirlenen prosedüre göre potasyum 2,6dimetilmorfolinditiyokarbamat (KDMMDTC) reaktifi sentezlenerek (Topuz 2004) bu reaktiften $0.01 \mathrm{~g}$ tart1lip deiyonize su ile $100 \mathrm{~mL}$ 'ye tamamlanmak suretiyle, \% 0.01 'lik çözeltisi hazırlanmıştır. Önderiştirme parametreleri için uygulanan deneyler ve cihaz ölçümlerinde kullanılan kalibrasyon çözeltileri için Co(II)'nin $0.5 \mathrm{molL}^{-1} \mathrm{HNO}_{3}$ 'teki $1000 \mathrm{mgL}^{-1}$ (Merck) stok çözeltisi kullanılmıştır. Co(II) çalışma ve kalibrasyon çözeltileri stok çözeltiden deiyonize su ile uygun seyreltmelerle hazırlanmıştır.
Co(II) iyonunun Amberlit XAD-4/SCHD reçinesi üzerinde sorpsiyonuna $\mathrm{pH}$ 'nın etkisinin incelenmesi amaciyla yükleme çözeltilerinin $\mathrm{pH}$ ayarlamalarında ve kolon şartlandırmasında 0.5 molL $^{-1} \mathrm{HNO}_{3}, \quad \mathrm{NH}_{3}$ ve derişik çözeltileri kullanılmıştır. Geliştirilen yöntemde çözelti pH'sını 4-6 aralığına ayarlamak için kullanılan $\mathrm{CH}_{3} \mathrm{COOH} / \mathrm{CH}_{3} \mathrm{COONa}$ tampon çözeltisi, 1 molL ${ }^{1} \quad \mathrm{CH}_{3} \mathrm{COONa}$ çözeltisine $1 \mathrm{molL}^{-1}$ $\mathrm{CH}_{3} \mathrm{COOH}$ çözeltisinin uygun hacminin eklenmesi ile hazırlanmıştır.

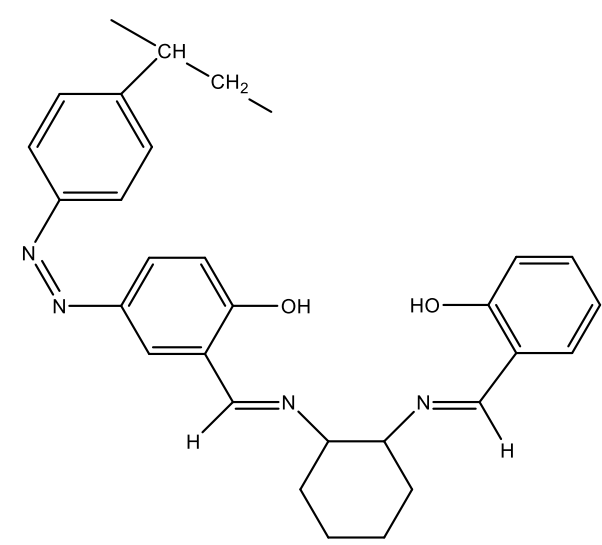

Şekil 1.Amberlit XAD-4/SCHD reçinesinin açık yapis1

\subsection{Amberlit XAD-4/SCHD Reçinesi ile Kolon Hazırlanması}

$1 \mathrm{~cm}$ iç çapında ve $5 \mathrm{~mL}$ hacminde kolonun iç kısmı cam pamuğu ile kapatılarak $0.2 \mathrm{~g}$ AmberlitXAD-4-N,N'-bis(salisilidin)-1,2'-

diaminosiklohegzan reçinesi ile doldurulmuş olup reçinenin üst kısmı da yine cam pamuğu ile kapatılmıştır. Temizleme işlemi için kolona doldurulmuş olan reçine üzerinden sırasıyla deiyonize su, $1 \mathrm{molL}^{-1} \mathrm{HNO}_{3}, 1 \mathrm{molL}^{-1} \mathrm{HCl}$ ve devamında asit kalıntıları uzaklaşana kadar deiyonize su ve ardındankolondan asetat tampon geçirilerek kolonun şartlandırılması gerçekleştirilmiştir. Her bir yıkama ve şartlandırma işleminden sonra çözeltideki Co(II) iyonunun önerilen yöntemle önderiştirilme işlemi yapılmıştır.

\subsection{Absorpsiyon Spektrumu}

UV-VIS spektrofotometrik tayin için, sentezlenen potasyum 2,6-dimetilmorfolinditiyokarbamat (KDMMDTC) ile Co(II) iyonlarının oluşturduğu yeşil renkli $\mathrm{Co}(\mathrm{DMMDTC})_{2}$ kompleksinin dalga boyuna karşı absorpsiyon spektrumları kör numunedeki absorpsiyon spektrumları ile birlikte 
incelenmiş ve sonuçlar Şekil 2'de gösterilmiştir. $\mathrm{Co}(\mathrm{II})$ iyonu kompleksinin maksimum absorbans1 $342 \mathrm{~nm}$ olarak gözlenmiştir ve kör çözeltileri bu dalga boyu değerinde absorbansı gözlenmemiştir.
Co(DMMDTC $)_{2}$ kompleksinin molar absorpsiyon kapasitesi $(\varepsilon), \quad 3.8 \times 10^{4} \quad \mathrm{Lmol}^{-1} \mathrm{~cm}^{-1} \quad$ olarak hesaplanmıştır.

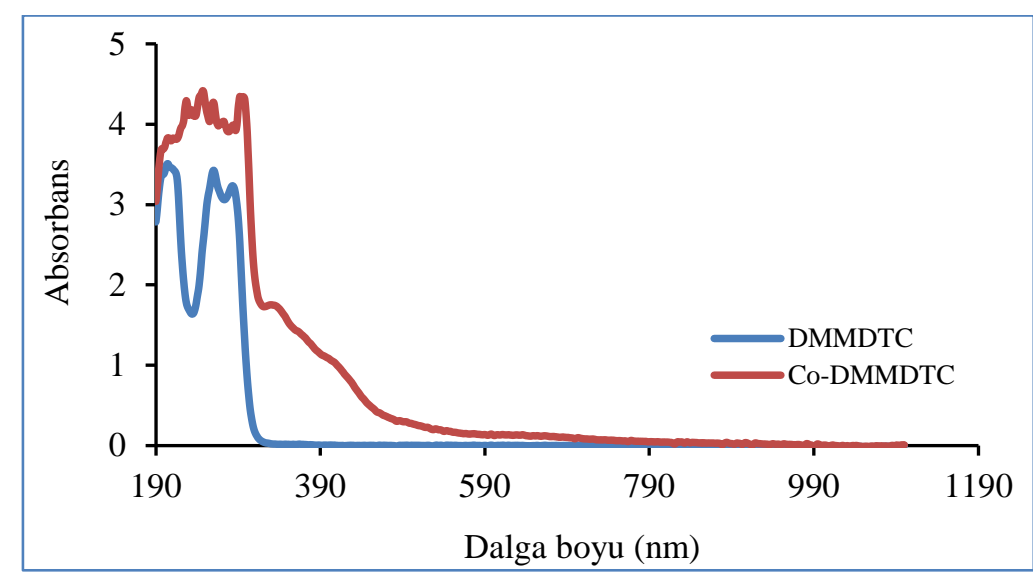

Şekil 2. Kör çözelti, DMMDTC ve Co(II)-DMMDTC spektrumları (Co(II) $2 \mathrm{mgL}^{-1}, \%$ 0,01 (w/v) KDMMDTC).

\subsection{Yöntem}

Önceden yıkama ve şartlandırılması yapılan $\mathrm{XAD}-4 / \mathrm{SCHD}$ kolonu üzerinden, asetat tamponu ile pH'sı 6-7 aralığına ayarlarlanan $100-1000 \mathrm{~mL}$ hacimli çevresel su numuneleri yaklaşık 2.5 mLdak $^{-1}$ akış hızında geçirilmiştir. Reçineye tutunan $\mathrm{Co}$ (II) iyonları, $3 \mathrm{mLdak}^{-1}$ akış hızında 10 $\mathrm{mL}, 1 \mathrm{molL}^{-1} \mathrm{HNO}_{3}$ çözeltisiyle elüe edilerek (sıyrılarak) geri alınmıştır. Önderiştirilen Co(II) iyonlarının absorbansları $\mathrm{pH}$ 6-7 aralığında 2,3 dimetilmorfolinditiyokarbamat

(DMMDTC) reaktifi ile 342 nm'de UV-VIS spektrofotometrede ölçülmüş ve kalibrasyon grafiğinden numunedeki $\mathrm{Co}(\mathrm{II})$ derişimi hesaplanmıştır. Geliştirilen yöntem, Bölüm 3.7'de verilen çevresel su numunelerininve seçilen standart referans maddenin içerdiği $\mathrm{Co}(\mathrm{II})$ derişiminin belirlenmesinde kullanılmıştır.

\subsection{Optimizasyon Stratejisi}

$\mathrm{Bu}$ çalışmada sorpsiyon ve elüsyon basamakları için kobalt iyonunun tayininde bağımsız parametrelerin etkisini belirlemek ve verim artırmak amaciyla bilgisayar istatistik programı MINITAB 17.1 programı ile yanıt yüzeyi dizaynı olan Box-Behnken Dizaynı kullanılarak optimum şartlar belirlenmiştir. George E. P. Box ve Donald Behnken tarafindan geliştirilen bu dizayn ile bağımlı değişkenler (geri kazanım ve sorpsiyon verimi) üzerinde birden fazla bağımsız değişkenin (pH, NH, NA, EA, EK, EH gibi) etkileri belirlendi
(Tablo 1). Dizayna göre oluşturulan her bir bağımlı değişken için 15 etaplık deneysel çalışma prosedürü sonunda her bir bağımlı değiş̧ken için cevap fonksiyonu adi verilen denklemler oluşturulup (Denklem 1) bağımlı ve bağımsız değişkenler arasındaki ilişki kolayca grafiklendirildi (Box ve Behnken, 1960; Montgomery, 1991).

$$
Y=\beta_{0}+\sum_{i=1}^{k} \beta_{i} X_{j}+\sum_{i=1}^{k} \beta_{i j} X^{2}+\sum_{i\rangle 1}^{k} \beta_{i j} X_{i} X_{j}
$$

Denklem 1'de $Y$ tahmin edilen cevap fonksiyonunu, $\beta_{0}, \beta_{i}, \beta_{i j}$ fonksiyon katsayılarını ve $X_{i}, \quad X_{j}, \quad X_{i j}$ bağımsız değişken parametrelerini belirtmektedir. Bilgisayar programı kullanılarak ANOVA analiz tabloları oluşturulmuş, yapılan analizlerin güvenirliliği ve her bir parametrenin diğer parametrelerle arasındaki ilişkiler ortaya konulmuştur.

Optimizasyon prosedürü, sorpsiyon ve elüsyon basamakları için en etkili deneysel koşulları belirlemek için kullanılmaktadır. Co(II) iyonunun tayin işlemine etki eden değişkenlerin cevabının araştırılması için deneylerin optimizasyonu, Box Behnken Dizayn Programı kullanılarak yapıldı. $\mathrm{Co}$ (II) iyonunun sorpsiyonu için $\mathrm{pH}$, numune akış hızı ve hacmi, elüent (geri kazanım çözeltisi) konsantrasyonu, hacmi ve akış hızı bağımsız değişkenleri optimize edildi. 
Tablo 1. Box behnkendizaynı istatistiksel analizi için kullanılan bağımsız değişkenler değerleri

\begin{tabular}{|c|c|c|c|}
\hline Bağımsız Değişkenler & Sembol & Düşük değer & Yüksek değer \\
\hline $\mathrm{pH}$ & $\mathrm{pH}$ & 2.7 & 5.7 \\
\hline Elüentin akış hızı (mldak $\left.{ }^{-1}\right)$ & EA & 0.6 & 3.2 \\
\hline Numunenin akış hızı $\left(\right.$ mldak $\left.^{-1}\right)$ & NA & 1.5 & 7 \\
\hline Elüentkonsantrasyonu $\left(\mathrm{molL}^{-1}\right)$ & EK & 0.5 & 4 \\
\hline Elüent hacmi (mL) & $\mathrm{EH}$ & 5 & 25 \\
\hline Numune hacmi (mL) & $\mathrm{NH}$ & 50 & 1500 \\
\hline
\end{tabular}

İstatistiksel analizde optimum değerlerin hassas bir şekilde saptanabilmesi için, $20 \mu \mathrm{g}$ Co(II) için üç tekrarlı ön denemeler gerçekleştirilmiş ve bulunan sonuçlar temel alınarak kullanılan bağımsız değişken değer aralıkları belirlenmiştir (Tablo 1).

\section{Bulgular ve Tartışma}

\section{1. pH Etkisi}

Co(II) iyonunun XAD-4/SCHD reçinesi üzerinde sorpsiyonu, sulu numune çözeltisinin $\mathrm{pH}$ 'sina yüksek oranda bağlıdır. Co(II)'nin sorpsiyon davranışı $\mathrm{pH} 1-12$ aralığında test edilmiştir. $20 \mu \mathrm{g}$
$\mathrm{Co}(\mathrm{II})$ içeren numune çözeltilerinin $\mathrm{pH}$ 's $\mathrm{HNO}_{3}$ ve $\mathrm{NH}_{3}$ çözetileri ile $1-12$ aralığına ayarlanarak kolon metodu ile bölüm 2.5 'de verilen yöntem uygulanmıştır. Şekil 2'de verilen sonuçlara göre düşük $\mathrm{pH}$ değerlerinde ekstraksiyon verimi, XAD4/SCHD reçinesinin aktif bölgelerinde protonlanmadan dolayı azalmıştır. Yüksek sorpsiyon verimi, protonlanmamış reçine yüzeyinden dolayı $\mathrm{pH} 2.7$ üzerinde elde edilmiştir. pH'nın 8'den yüksek olduğu değerlerde Co(II) iyonunun $\mathrm{pH}$ ayarlamalarında kullanılan $\mathrm{NH}_{3}$ ile $\mathrm{Co}\left(\mathrm{NH}_{3}\right)_{6}{ }^{2+}$ kompleksi oluşturma eğiliminden dolayı ekstraksiyon verimi düşmüştür. Bu nedenle $\mathrm{pH}$ değişkeninin optimizasyon dizaynında kullanılması için 2.7-5.7 aralığı kullanılmıştır.

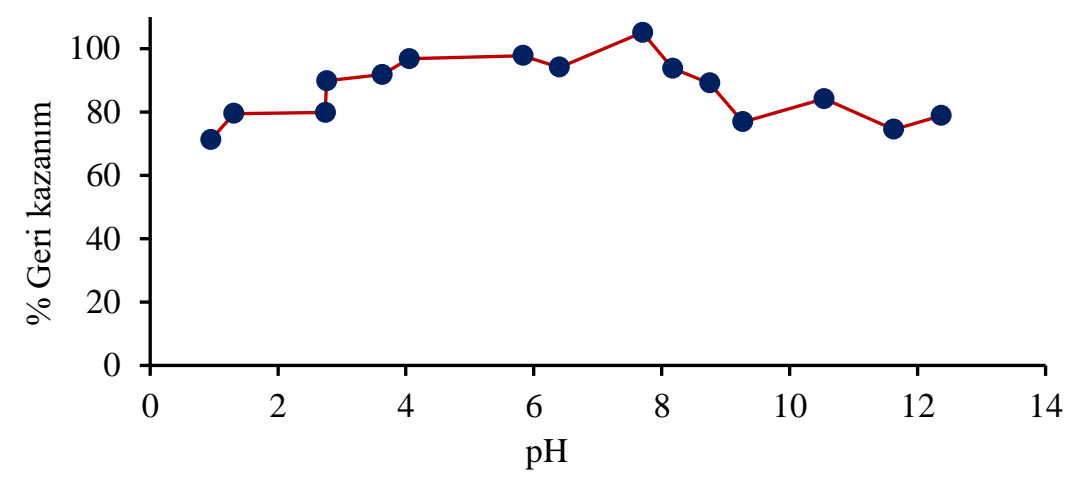

Şekil 2. Numune çözeltisinin pH'sınınCo(II) iyonunun XAD-4/SCHD üzerine sorpsiyonuna etkisi.

\subsection{Elüentin Türü ve Konsantrasyonu Etkisi}

XAD-4/SCHD üzerinde sorplananCo(II) iyonu miktar1, farkl1 konsantrasyonlardaki $\mathrm{HNO}_{3}, \mathrm{HCl}$, EDTA, $\mathrm{H}_{3} \mathrm{PO}_{4}$ ve $\mathrm{CH}_{3} \mathrm{COOH}$ çözeltileri ile kolondan geri kazanılarak Bölüm 2.5'de verilen UV-VIS spektrofotometrik metot ile tayin edildi. Şekil 3'de verilen sonuçlardan, Co(II) iyonunun desorpsiyonu için $1 \mathrm{molL}^{-1} \mathrm{HNO}_{3}$ çözeltisinin $\% 99$ geri kazanımla en uygun elüsyon çözeltisi olduğu belirlendi.

\subsection{Elüent Çözeltisi Hacminin Etkisi}

Reçinede tutunan $\mathrm{Co}(\mathrm{II})$ iyonunun geri kazanımı için $1 \mathrm{molL}^{-1} \mathrm{HNO}_{3}$ çözeltisinin $2-25 \mathrm{~mL}$ hacim aralığındaki hacimler kullanılarak ölçülen Co(II) konsantrasyonundan \% geri kazanım değerleri belirlenmiş̧ir. Şekil 4'de elde edilen sonuçlardan elüent hacminin $5 \mathrm{ml}$ ve üzerinde en az $\% 90$ geri kazanım değeri elde edildiği belirlenmiştir. 


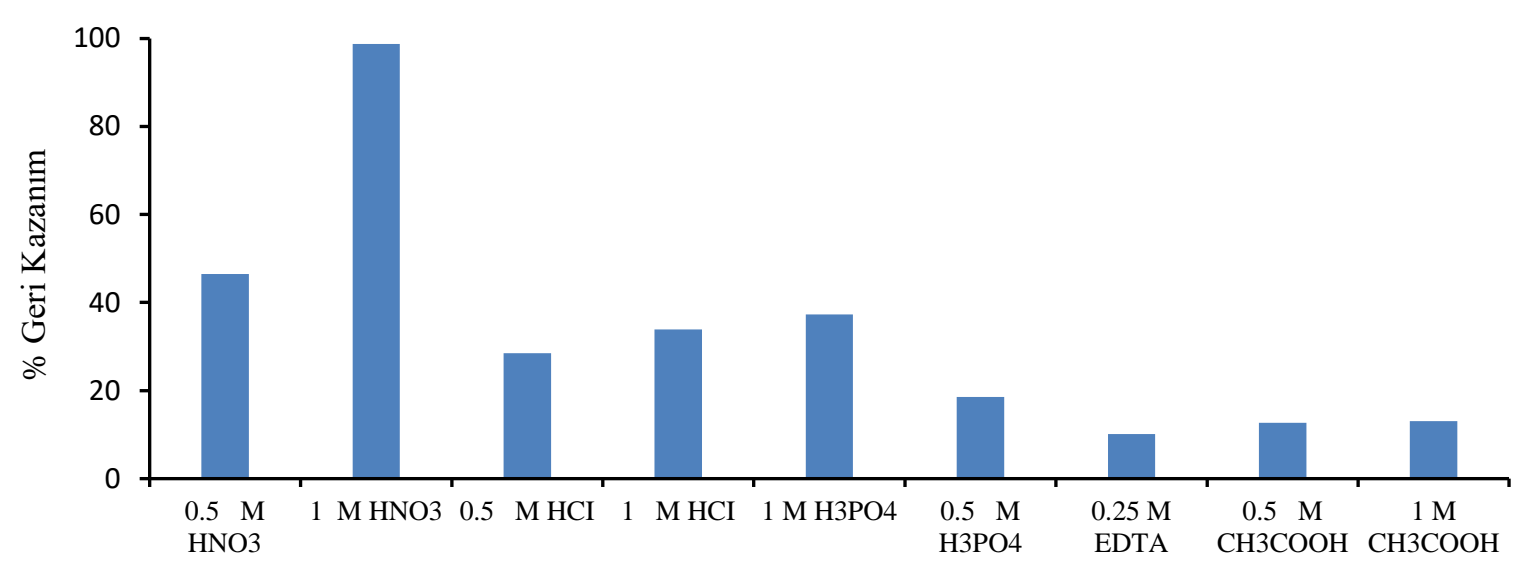

Şekil 3.Co(II)'ninelüasyonuna geri kazanım çözeltisinin türü ve derişiminin etkisi.

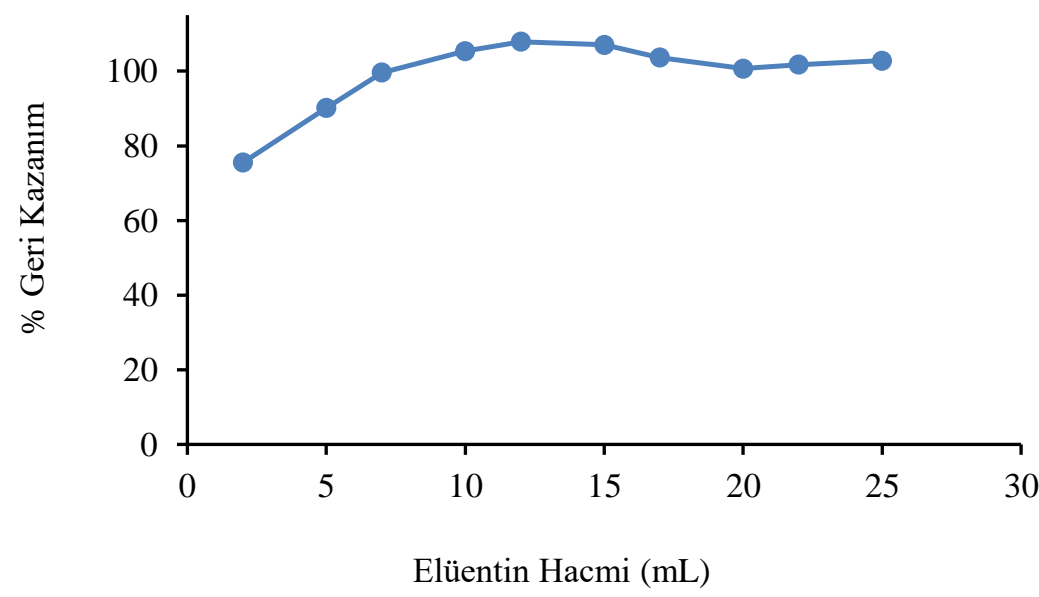

Şekil 4. Co(II)'nin elüasyonuna elüent hacminin etkisi.

\subsection{Sorpsiyon ve Elüasyona Akış Hızının Etkisi}

$20 \mu \mathrm{g}$ Co(II) içeren ve pH's14-6'ya ayarlanan 50 $\mathrm{mL}$ hacimli model numune çözeltileri,0.78.0 $\mathrm{mLdak}^{-1}$ akış hızında XAD-4/SCHD kolonundan geçirildi ve elüe edildikten sonra Co(II) iyon içerikleri UV-VIS spektrofotometri ile tayin edildi. Şekil 5'de gösterilen sonuçlardan, 3 mLdak $^{-1}$ üzerindeki numune akış hızında Co(II)'nin sorpsiyonunun azaldığ gözlenmiştir. $\mathrm{Bu}$ yüzden \% 98 geri kazanımla $3 \mathrm{mLdak}^{-1}$ sorpsiyon akış hızı optimum olarak seçilmiştir. Benzer şekilde, $0.5-7 \mathrm{mLdak}^{-1}$ elüent akış hızı aralı̆̆ında, elüasyon verimi de $2 \mathrm{mLdak}^{-1}$ dan sonra azaldığı gözlenmiştir.

\subsection{Numune Hacminin Etkisi}

Yüksek önderiştirme faktörü elde etmek için numune hacminin de yüksek olması istenir. Co(II) iyonunun $\mathrm{XAD}-4 / \mathrm{SCHD}$ reçinesi üzerinde sorpsiyonuna 25-1600 mL aralığında numune hacminin etkisi araştırıldı. Şekil 6'da verilen sonuçlara göre, $1000 \mathrm{~mL}$ 'ye kadar numune hacminde \%100-110 aralığında geri kazanım değerleri elde edilmiştir. Buna göre $10 \mathrm{~mL}$ ölçüm çözeltisiyle önderiştirme faktörünün 100 olduğu görülmektedir.

\subsection{Yabancı İyon Etkisi}

$20 \mu \mathrm{g}$ Co(II) içeren $50 \mu \mathrm{mL}$ hacimli model çözeltilerin önerilen yöntemle geri kazanımına ayrı ayrı alkali, toprak alkali, bazı anyon ve geçiş metallerinin yabancı iyon olarak etkileri araştırıldı. \%95 ve \%105 sınırındaki geri kazanım değerleri tolerans limit sınırları olarak belirlendi. Tablo 2'de verilen sonuçlardan da anlaşlacağı gibi, araştırılan anyon ve katyonların belirlenen miktarlarında önemsenmeyecek oranda girişimin olduğu görülmektedir. 


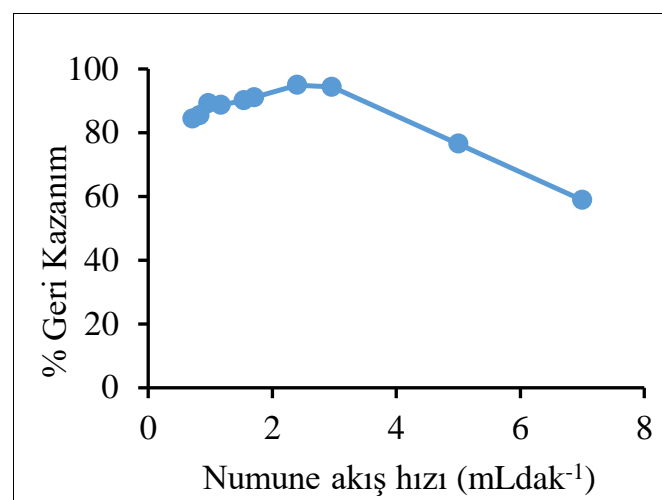

(a)

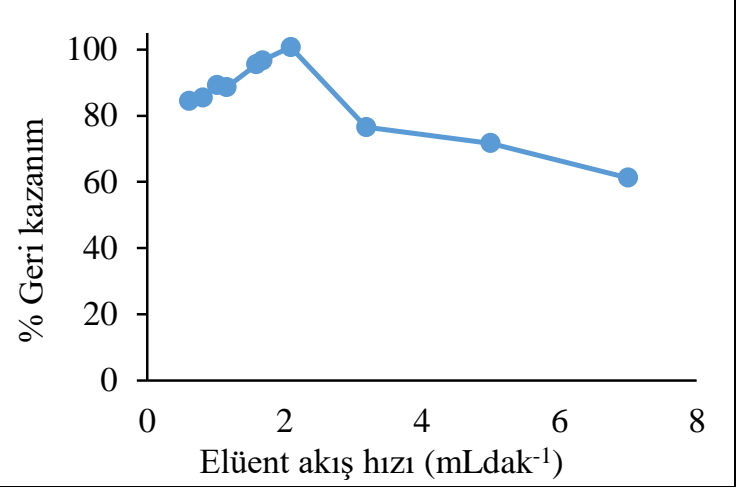

(b)

Şekil 5. Co(II)'nin sorpsiyon(a) ve elüasyonuna (b) akış hızının etkisi.

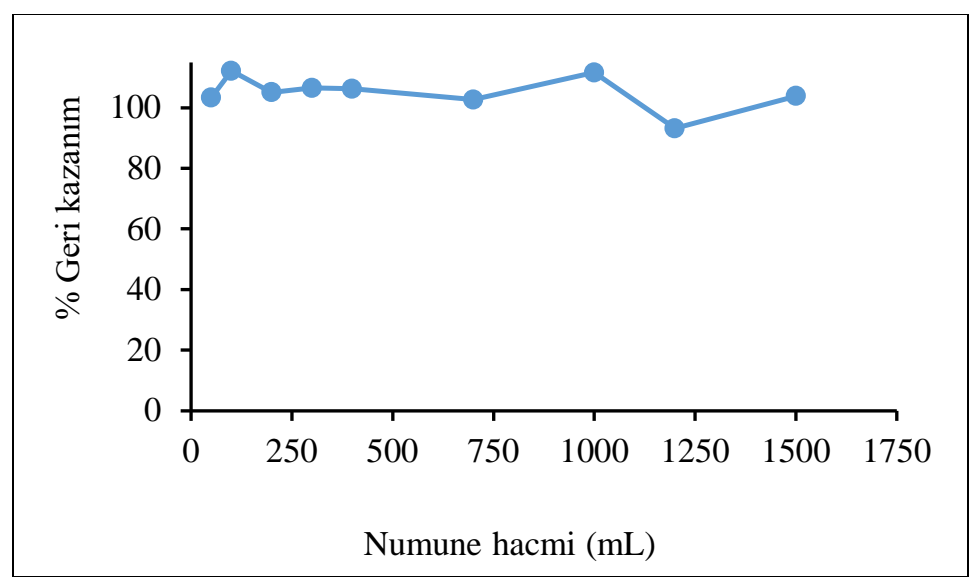

Şekil 6. $\mathrm{Co}(\mathrm{II})$ iyonunun $\mathrm{XAD}-4 / \mathrm{SCHD}$ reçinesi üzerinde sorpsiyonuna numune hacminin etkisi.

Tablo 2. Co(II)'nun önderiştirilmesine yabancı iyon etkisi.

\begin{tabular}{|l|l|l|l|}
\hline İyon & Miktar $(\boldsymbol{\mu g})$ & Eklenen & Co(II) için \% Geri Kazanım \\
\hline $\mathrm{Cl}^{-}$ & 20000 & $\mathrm{NaCl}$ & 98.2 \\
\hline $\mathrm{NO}_{3}{ }^{-}$ & 20000 & $\mathrm{KNO}$ & 35.4 \\
\hline $\mathrm{K}^{+}$ & 20000 & $\mathrm{KCI}$ & 90.4 \\
\hline $\mathrm{CO}_{3}^{2-}$ & 20000 & $\mathrm{Na}_{2} \mathrm{CO}_{3}$ & 102.6 \\
\hline $\mathrm{SO}_{4}^{2-}$ & 20000 & $\mathrm{Na}_{2} \mathrm{SO}_{4}$ & 96.8 \\
\hline $\mathrm{I}^{-}$ & 20000 & $\mathrm{KI}$ & 98.2 \\
\hline $\mathrm{Ca}^{2+}$ & 20000 & $\mathrm{Ca}\left(\mathrm{NO}_{3}\right)_{2} 4 \mathrm{H}_{2} \mathrm{O}$ & 103.2 \\
\hline $\mathrm{Mg}^{2+}$ & 20000 & $\mathrm{MgCI}$ & 101.5 \\
\hline $\mathrm{Na}^{+}$ & 20000 & $\mathrm{NaF}$ & 94.3 \\
\hline $\mathrm{Mn}^{2+}$ & 500 & $\mathrm{MnCl} 2 \mathrm{H}_{2} \mathrm{O}$ & 101.2 \\
\hline \multirow{2}{*}{$\mathrm{Cu}^{2+}$} & 500 & \multirow{2}{*}{$\mathrm{Cu}\left(\mathrm{NO}_{3}\right)_{2}$} & 122.9 \\
\cline { 2 - 4 } & 250 & $\mathrm{Ni}\left(\mathrm{NO}_{3}\right)_{2}$ & 104.3 \\
\hline $\mathrm{Ni}^{2+2}$ & 500 & \multirow{2}{*}{$\mathrm{Cd}\left(\mathrm{NO}_{3}\right)_{2}$} & 103.5 \\
\hline \multirow{2}{*}{$\mathrm{Cd}^{2+}$} & 500 & \multirow{2}{*}{$\mathrm{Fe}\left(\mathrm{NO}_{3}\right)_{3}$} & 73.43 \\
\cline { 2 - 3 } & 250 & & 104.3 \\
\hline \multirow{2}{*}{$\mathrm{Fe}^{3+}$} & 500 & 101.2 \\
\cline { 2 - 3 } & 250 & 92.05 \\
\hline
\end{tabular}




\subsection{Metodun Geçerliliği ve Uygulamaları}

Tablo 3'de yöntemin kalibrasyon grafiğginin korelasyon katsayısı $\left(r^{2}\right)$ değeri, gözlenebilme ve tayin sınırı verilmiştir. Co(II) iyonu için gözlenebilme sınırı ve tayin limiti (sınırı) değerleri için, 20 adet kör çözeltiye Bölüm $2.5^{\circ}$ de verilen yöntem uygulanarak $342 \mathrm{~nm}$ dalga boyundaki absorbans değerlerinin standart sapmas1 hesaplandi. Standart sapmanın, gözlenebilme sınırı değeri için 3 katına, tayin sınırı için 10 katına karşılık gelen Co(II) iyon konsantrasyonu hesaplandi. Bu konsantrasyonlar zenginleştirme faktörü olan 100 rakamına bölünerek zenginleştirmeden önceki konsantrasyonlar hesaplandi. Ayrıca $10 \mu \mathrm{g} \mathrm{Co}$ (II) içeren çözeltilere $(n=4)$ önerilen yöntemin uygulanması sonucunda \% BSS değeri 1.9 olarak bulunmuştur. $\% 5$ 'den küçük BSS değeri yöntemin tekrarlanabilirliğini göstermektedir.

Tablo 3. Metodun analitiksel özellikleri

\begin{tabular}{|l|l|}
\hline Korelasyon katsayısı $\left(\mathrm{r}^{2}\right)$ & 0.9980 \\
\hline Gözlenebilme sınırı $\left(\mathrm{mgL}^{-1}\right)$ & 0.0084 \\
\hline Tayin sınırı $\left(\mathrm{mgL}^{-1}\right)$ & 0.0638 \\
\hline Doğrusal aralık $\left(\mu \mathrm{gmL}^{-1}\right)$ & $0.06-3$ \\
\hline \%BSS* $(\mathrm{n}=4)$ & 1.9 \\
\hline Geri Kazanım Faktörü & 100 \\
\hline *BSS: Băıl standart sapma
\end{tabular}

*BSS: Bağıl standart sapma

Tablo 4. Sertifikalı standart madde analiz sonucu

\begin{tabular}{llll}
\hline $\begin{array}{l}\text { Sertifikalı standart su } \\
\text { numunesi }\end{array}$ & $\begin{array}{l}\text { Sertifikalı } \\
\text { Co(II) değeri }\left(\mu \mathrm{gL}^{-1}\right)\end{array}$ & $\begin{array}{l}\text { Bulunan } \\
\mathrm{Co}(\mathrm{II}) \text { değeri }\left(\mu \mathrm{gL}^{-1}\right)\end{array}$ & (\%) Geri Kazanım \\
\hline NW-TMDA-70.2 & $290 \pm 21^{*}$ & $310 \pm 6$ & $\% 106.8$ \\
\hline
\end{tabular}

*\%95 güven seviyesinde dört ölçümün ortalaması $(\bar{X} \pm t s / \sqrt{N})$

Tablo 5. Farklı su numunelerinin önerilen metot ve ICP-MS metodu ile bulunan Co(II) içeriklerinin karşılaştırılması

\begin{tabular}{llll}
\hline Metot & Doğanc1 Mudurnu Çayı $\left(\mu \mathrm{gL}^{-1}\right)$ & Musluk suyu $\left(\mu \mathrm{gL}^{-1}\right)$ & Sizıntı suyu $\left(\mu \mathrm{gL}^{-1}\right)$ \\
\hline ICP-MS & $0.23 \pm 0.06^{*}$ & $0.15 \pm 0.25$ & $66.8 \pm 3.35$ \\
\hline Önerilen & $0.35 \pm 0.09$ & $0.17 \pm 0.10$ & $71.4 \pm 1.8$ \\
\hline
\end{tabular}

\footnotetext{
* \%95 güven seviyesinde dört ölçümün ortalaması $(\bar{X} \pm t s / \sqrt{N})$
}

Önerilen yöntemin doğruluğunu belirlemek amaciyla sertifikalı standart su numunesi (NWTMDA-70.2), Bölüm 2.5 'de verilen yönteme göre analiz edilmiş ve hesaplanan sonuçlarının sertifikalı değerlerle uyumlu olduğu gözlemlenmiştir (Tablo 4). Yöntemin doğruluğu kanıtlandıktan sonra geliştirilen yöntem son olarak farklı çevresel su numunelerine, içerdikleri Co(II) miktarlarının tayini için uygulanmış ve sonuçlar ICP-MS yöntemi ile karşılaştırılmıştır. (Tablo 5).

$\mathrm{Bu}$ çalışmada çevresel su numunesi olarak Ankara Mogan Gölü ve Bolu ve çevresinden, Gölköy bölgesi göl ve kaynak suyu, katı atık depolama sahası sızıntı suyu, organize sanayi bölgesi (metal sanayi) atıksuyu, Karaköy büyüksu deresi, doğanc1 mudurnu çayı ve araştırma laboratuvarı musluk suyu kullanılmıştır. Önerilen metot ile analiz edilecek çevresel su numuneleri $0.45 \mu \mathrm{m}$ gözenek genişliğindeki selüloz-nitrat filtreden vakumla süzülmüştür. Süzüntü asit ve deiyonize suyla yıkanmış şişelere alınarak birkaç gün içerisinde geliştirilen yöntemle analiz edilmiştir. Çeşme suyu numuneleri ise hiçbir ön işlem yapılmadan doğrudan kullanılmışıır. 100-1000 $\mathrm{mL}$ hacimli su numunelerine farklı derişimlerde Co(II) iyonu ayrı ayrı eklenerek (Ekleme / geri kazanma) ve eklenmeden metal içerikleri Bölüm 2.5 'de verilen yönteme göre belirlenmiştir (Tablo $6)$. 
Tablo 6. Farklı çevresel su numunelerinin önerilen metot ile bulunan Co(II) analiz sonuçları

\begin{tabular}{|l|l|l|l|}
\hline \multirow{2}{*}{ Numune } & \multicolumn{2}{l|}{ Co(II) $\left(\boldsymbol{\mu g L}^{-\mathbf{1}}\right)$} & \multirow{2}{*}{ Geri Kazanım (\%) } \\
\cline { 2 - 4 } & Eklenen & Bulunan & \\
\hline \multirow{2}{*}{ Mogan Gölü (Ankara) } & - & $9 \pm 5.0^{*}$ & \\
\cline { 2 - 4 } & 20 & $27.90 \pm 2.50$ & 96.2 \\
\hline \multirow{2}{*}{ Karaköy Büyüksu Deresi (Bolu) } & - & $25.90 \pm 0.84$ & \\
\cline { 2 - 4 } & 20 & $46.80 \pm 0.42$ & 102.1 \\
\hline \multirow{2}{*}{ Gölköy Kaynak Çeşmesi (Bolu) } & - & $16.80 \pm 0.81$ & \\
\cline { 2 - 4 } & 40 & $56.70 \pm 0.55$ & 96.5 \\
\hline \multirow{2}{*}{ Gölköy Gölü (Bolu) } & - & $<\mathrm{T} . S$. & \\
\hline \multirow{2}{*}{ Arçelik Atıksuyu (Bolu) } & 100 & $101.8 \pm 1.8$ & 102.0 \\
\hline
\end{tabular}

* \%95 güven seviyesinde dört ölçümün ortalaması $(\bar{X} \pm t s / \sqrt{N})$, T.S.: Tayin Sınırı

\subsection{Değiş̧kenlerin Optimizasyonu}

Yanıt yüzey yönteminde örnekleme yöntemi olarak tanımlanan Box-Behnken tasarımı "Denemelerin Optimum Koşullara Ulaşması" ismi ile 1951 yilinda Box and Wilson tarafindan geliştirilmiş ve genel olarak "Proseslerin geliştirilmesi ve optimizasyonu için gerekli istatistiksel ve matematiksel tekniklerin birlikte kullanıldığı bir yöntem” olarak tanımlamıştır.

Çalışmada öncelikle Box-Behken istatistiksel analizine uygun olarak bağımsız değişken aralıkları belirlenmiş ve istatistiksel olarak oluşturulan 15 etaplık deneysel çalışma prosedürüne göre deneysel çalışmalar gerçekleştirilmiştir. Deneysel çalışmalar sonucunda elde edilen bağımlı değișken sonuçları Minitab17.1 programı vasıtasıyla analiz edilmiştir. Analiz sonucunda oluşturulan bağıml ve bağımsız değişkenler arasındaki ilişkiyi ifade eden denklemler elde edilmiştir (Denklem 1 ve 2). Deneysel olarak bulunan değerlerin istatistiksel değerler ile uyumluluğu ( $\mathrm{R}^{2}$ sorpsiyon: 0,95 ve $\mathrm{R}^{2}$ elüsyon: 0,99$)$ ve istatistiksel analiz metodu seçimi ( $\mathrm{R}^{2}$ sorpsiyon(adj): 0,86 ve $\mathrm{R}^{2}$ elüsyon(adj) : 0,97) denetlenerek istatistiksel olarak optimum değerler tespit edilmiştir. Bu sonuçlar deneysel çalışmaların istatistiksel olarak da ifade edilebileceğini göstermiştir. Aynı zamanda istatistiksel analiz vasitasiyla, parametreler arasındaki ilişki de 3 boyutlu yanıt-yüzey grafiklerle ifade edilmiştir.

$y=-51,7+44,77 p H+7,27 N A-0,0258 N H-3,001 p H^{2}-0,895 N A^{2}-0,000005 N H^{2}-$
$0,776 p H * N A-0,00048 p H * N H+0,00649 N A * N H$

$y=-73,3+47,62 E A+9,165 E H+22,07 E K-9,76 E A^{2}-0,3192 E H^{2}-3,077 E K^{2}-$

$0,293 E A * E H+0,48 E A * E K+0,621 E H * E K$

SPE değişkenleri için tahmini yanıt yüzey çalışması olarak sorpsiyon için $[\mathrm{NA}] /[\mathrm{pH}],[\mathrm{NH}] /$ $[\mathrm{pH}],[\mathrm{NH}] /[\mathrm{NA}]$ elüsyon için $[\mathrm{EK}] /[\mathrm{EH}],[\mathrm{EK}] /$ $[\mathrm{EA}], \quad[\mathrm{EA}] /[\mathrm{EH}]$ Şekil 7 ve 8 'de gösterilmiştir.Sorpsiyon ve elüasyon değişkenleri arasında üç boyutlu (3D) yanıt yüzey çizildikten sonra \%100' e yakın geri kazanım elde edilebilen değișkenlerin teorik değerlerini hesaplamak için kuadratik eşitlik kullanıldı.Şekil 7'desorpsiyon için NH, NA ve pH bağımsız değişkenlerinin geri kazanım üzerine etkisi gösterilmiştir.NH ortalama değeri olan $775 \mathrm{~mL}$ sabit tutularak $\mathrm{pH}$ ve NA değerlendirildiğinde $\mathrm{pH}$ değerinin çok etkili olduğu görülmektedir. Özellikle nötral değerlerde geri kazanım değerinin \%95'e kadar yükseldiği belirlenmiștir (Sekil 7a). NA $4.25 \mathrm{mldk}^{-1}$, da sabit tutulduğunda ise yine $\mathrm{pH}$ değerinin nötral seviyelerde gerikazanım değerlerinin maksimum 
seviyeye ulaştırdığı gözlenmiştir. NH parametresinin $\mathrm{pH}$ kadar etkili olmadığ görülmüştür (Şekil 7b). Her iki grafik incelendiğinde $\mathrm{pH}$ bağımsız değişkeninin işlemin kontrolü üzerinde çok etkili olduğu belirlenerek nötralpH değerlerinde geri kazanım değerini maksimize ettiği dikkate alınarak $\mathrm{pH}$ orta değer olan 5.7 de sabit tutulmuş $\mathrm{NH}$ ve NA etkisi incelenmiştir (Şekil 7c). NH değişkenini düşük, NA değişkeni ise daha yüksek tutulduğunda geri kazanımın en yüksek değerde başarılabileceği tespit edilmiştir. Sonuç olarak üç bağımsız değişken değerlendirildiğinde gerikazanım değerini sorpsiyon için maksimize etmek için $\mathrm{pH}$ değişkeninin en önemli parametre olduğu görülmüş ve aynı zamanda yapılan istatistiksel analiz sonucunda en etkili \% geri kazanım değerini sağlamak amaciyla optimum $\mathrm{pH}$ : 7.2, $\mathrm{NH}: 50 \mathrm{~mL}$ ve NA: $1.5 \mathrm{mLdk}^{-1}$ olduğu tespit edilmiştir.

(a)

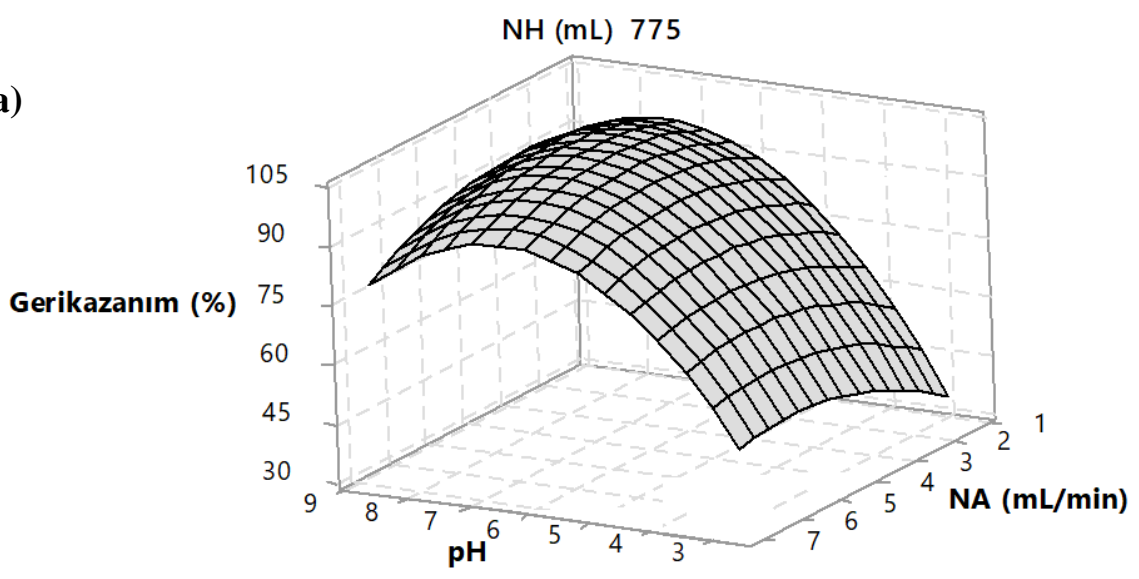

(b)

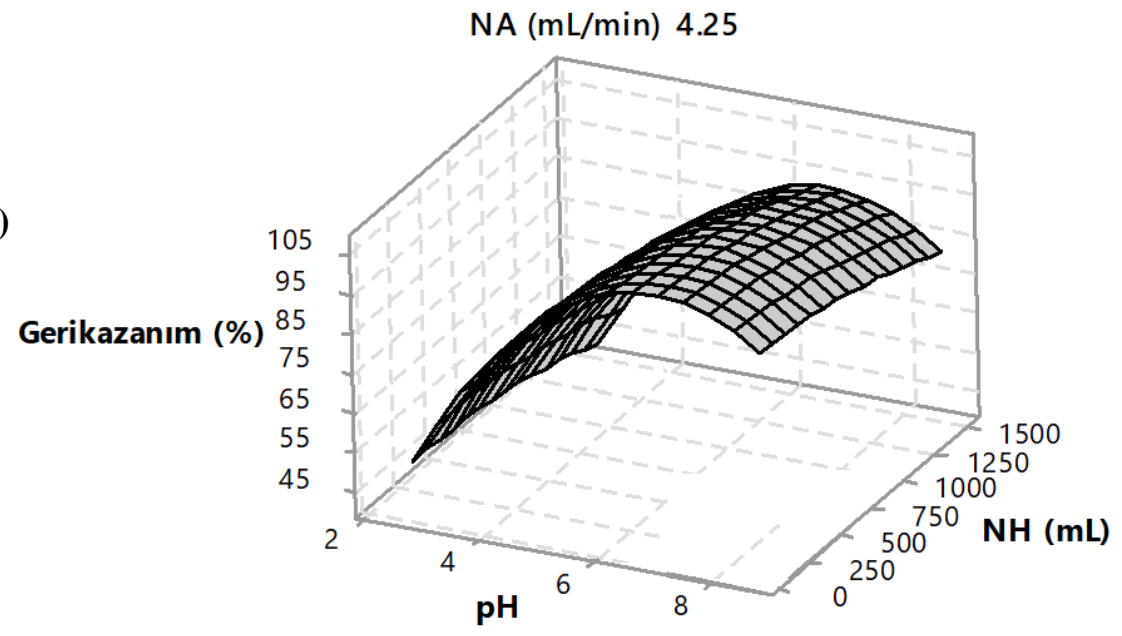

(c)

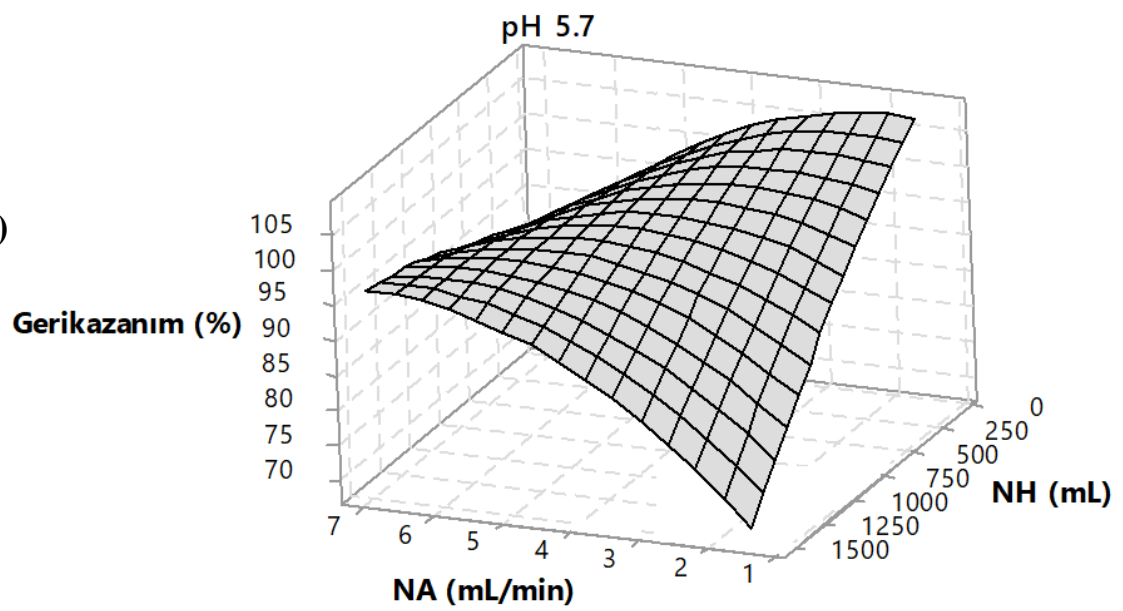

Şekil 7. Sorpsiyon için geri kazanım üzerinde (a) $\mathrm{pH}$ ve $\mathrm{NA}(\mathrm{NH}=775 \mathrm{ml}$ için), (b) $\mathrm{pH}$ ve $\mathrm{NH}(\mathrm{NA}=4.25$ mLdak $^{-1}$ için), (c) NA ve NH (pH= 5.7 için) etkisi. 

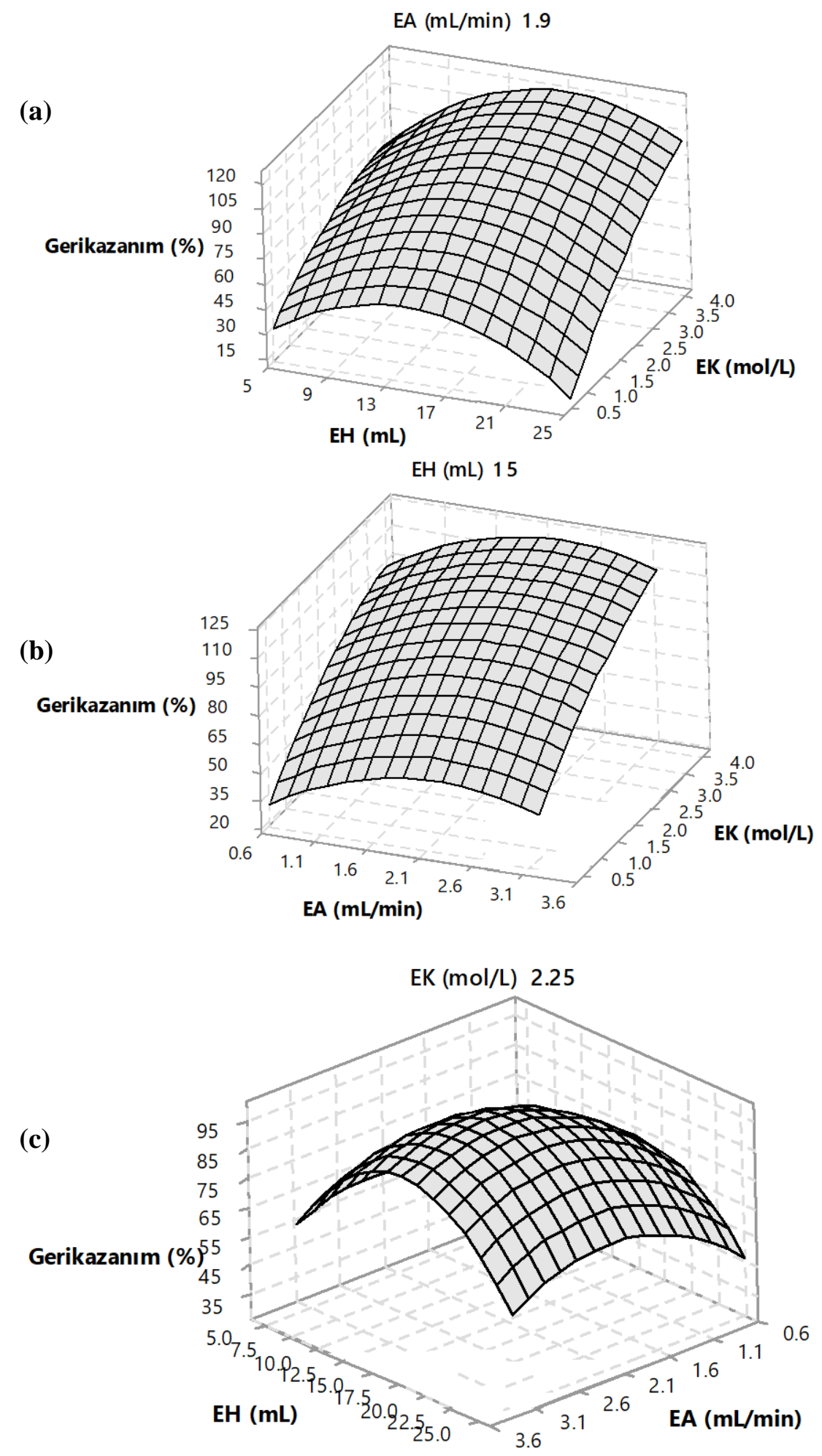

Şekil 8. Elüasyon için geri kazanım üzerinde (a) $\mathrm{EH}$ ve EK (EA=1.9 $\mathrm{mLdak}^{-1}$ için), (b) $\mathrm{EA}$ ve $\mathrm{EK}(\mathrm{EH}=15$ mLiçin), (c) $\mathrm{EH}$ ve $\mathrm{EA}\left(\mathrm{EK}=2.25 \mathrm{molL}^{-1}\right.$ için) etkisi.

Elüasyon için yapılan geri kazanım testlerinde sorpsiyon değerlerinde olduğu gibi 3 bağımsız değişkenin (EH, EK ve EA) etkileri araştılmıştır. EA $1.9 \mathrm{mLdk}^{-1}$ da sabit tutulduğunda $\mathrm{EH}$ 'ye nispetle EK bağımsız değişkeninin daha etkili olduğu sistemin performansını artırmak için EK değerinin yükseltilmesi gerektiği görülmüştür
(Şekil 8a). Benzer şekilde EH: $15 \mathrm{~mL}$ 'de sabit tutulduğunda yine EA'dan daha fazla EK'nın etkili olduğu tespit edilmiştir (Şekil 8b). EK nın geri kazanım üzerindeki önemli etkisi görüldüğünden EK bağımsız değişkeni 2.25 molL 1 ortalama değerinde sabitlenerek EH ve EA parametrelerinin ortalama değerlerinde geri 
kazanım değerini maksimize ettiği görülmüştür (Şekil 8c). Şekil 7'de verilen grafikler topluca değerlendirildiğinde geri kazanım bağımlı değişkeni üzerinde en etkili olanın EK bağımsız değişkeni olduğu, EA ve EH değişkenlerinin EK kadar olmasa da gerikazanım değerini bir miktar değiştirdikleri belirlenmiştir. İstatistiksel olarak yapılan değerlendirmede ise yüksek \% geri kazanım değeri sağlamak amacıyla optimum EA: $2.3 \mathrm{mLdk}^{-1} \mathrm{EH}: 17.1 \mathrm{~mL}$ ve EK: $4 \mathrm{mLdk}^{-1}$ olduğu tespit edilmişsir.

Tablo 7. UV-VIS Spektrofotometre, ICP-AES ve FAAS ile kobalt(II) tayini için farklı katı faz ekstraksiyon yöntemlerinin karşılaştırılması.

\begin{tabular}{|c|c|c|c|c|c|c|}
\hline ADSORBAN & pH & ELÜENT & CIHAZ & $\mathbf{Z F}$ & $\operatorname{LOD}\left(\mu \mathrm{gL}^{-1}\right)$ & REFERANS \\
\hline $\begin{array}{l}\text { Amberlite XAD-2- } \\
\text { pyrocatechol }\end{array}$ & $7.0-8.0$ & $\mathrm{HCl} / \mathrm{HNO}_{3}$ & FAAS & 23 & 0.59 & Lemos vd., 2006 \\
\hline Amberlite XAD-1180 & 9.0 & $\begin{array}{l}1 \mathrm{M} \mathrm{HNO}_{3} \\
\text { (Aseton } \\
\text { içinde) }\end{array}$ & FAAS & 100 & 110 & Soylak vd., 2003 \\
\hline $\begin{array}{l}\text { Amberlite XAD-2- } \\
\text { Nitroso R-tuzu }\end{array}$ & $6.5-8.0$ & $\mathrm{HCI}$ & FAAS & 79 & 1.25 & Lemos vd., 2003 \\
\hline $\begin{array}{l}\text { XAD-2-2-(2- } \\
\text { Thioazolylazo)-p- } \\
\text { kresol }\end{array}$ & 8.0 & HCI & ICP-AES & 100 & 12 & $\begin{array}{l}\text { Ferreira ve De } \\
\text { brito, } 1999\end{array}$ \\
\hline Politetrafloroetilen & 5.5 & Kloroform & $\begin{array}{l}\text { UV-VIS } \\
\text { Spektrofotometre }\end{array}$ & 100 & 1.2 & Hejazi vd., 2004 \\
\hline Yüklü silika jel & 9.2 & $6 \mathrm{M} \mathrm{HNO}_{3}$ & $\begin{array}{l}\text { UV-VIS } \\
\text { Spektrofotometre }\end{array}$ & 7.21 & 0.51 & $\begin{array}{l}\text { Teixeira Tarley } \\
\text { vd., } 2011\end{array}$ \\
\hline $\begin{array}{l}\text { Amberlit-XAD- } \\
\text { 4/SCHD }\end{array}$ & 5 & $1 \mathrm{M} \mathrm{HNO}_{3}$ & \begin{tabular}{|l|} 
UV-VIS \\
Spektrofotometre
\end{tabular} & 100 & 8.4 & Bu çalışma \\
\hline
\end{tabular}

ZF: Zenginleştirme Faktörü; ICP-AES: İndüktif Eşleşmiş Plazma Atomik Emisyon Spektroskopisi; FAAS: Alevli Atomik Absorpsiyon Spektroskopisi

\section{Sonuç}

$\mathrm{Bu}$ çalışmada. SCHD ile modifiye edilmiş Amberlit XAD-4 reçinesi kullanılarak çevresel su numunelerinden Co(II)'nin ayrilmasi ve önderiştirilmesi ve akabinde önerilen DMMDTC ligantıyla kullanımı kolay, ucuz ve ek bir teknik bilgi gerektirmeyen UV-VIS spektrofotometrik yöntemle $\mathrm{Co}$ (II) iyonunun analizi gerçekleştirilmiştir. Son yıllardaki metal zenginleştirme çalışmalarında ligand ile modifiye edilmiş reçinelerin kullanımı ile kolon kapasitesinin ve zenginleştirme faktörünün daha yüksek, tayin sınırının daha düşük olduğu gözlemlenmiştir. Co(II) iyonunun önerilen SPE yöntemiyle elde edilen 100 kat zenginleştirilmesi ve sudaki matriks iyonlarından etkili bir şekilde ayrılması sağlanmıştır. Ayrıca, önerilen yöntemin düşük tayin sınırı sayesinde standart su numunesinde \%95'in üzerinde geri kazanım sağlanmış ve ICP-MS yönteminden elde edilen sonuçlarla da uyum içerisinde olduğu tespit edilmiş doğruluğu, kesinliği ve hassasiyeti yüksek bir yöntemin geliştirilmiş olduğu kanıtlanmıştır.
Yapılan deneysel ve istatistiksel çalışmaların sonucunda geri kazanım değeri üzerinde en etkili bağımsız değişken parametresinin; sorpsiyon işleminde $\mathrm{pH}$, elüasyon işleminde $\mathrm{EK}$ olduğu tespit edilmiştir. Buna göre maksimum geri kazanım değerinin sorpsiyon işleminde $\mathrm{pH}: 7.2$, $\mathrm{NH}: 50 \mathrm{~mL}$ ve $\mathrm{NA}: 1.5 \mathrm{mLdk}^{-1}$. elüasyon işleminde ise EA: $2.3 \mathrm{mLdk}^{-1}$, EH:17.1 mL ve EK: 4 molL $^{-1}$ olduğu, bu bağımsız değişken değerlerinin uygulanması ile \%100 geri kazanım değerleri sağlanabileceği tespit edilmiştir. Tablo 7'de farklı enstrümental cihazlarla tayin edilen $\mathrm{Co}$ (II) iyonu için katı faz ekstraksiyon yöntemleri karşılaştırılmış ve önerilen yöntemin zenginleştirme faktörü ve tayin limiti ile diğer çalışmalara göre avantajlı olduğu gözlemlenmiştir.

\section{Kaynaklar}

Alpdoğan, G., 2016. Solid phaseextraction of $\mathrm{Cu}$ (II), Ni (II), Co (II) and Fe (III) ions in water samples using salicylaldehydebenzoylhydrazone on Amberlite XAD-4 and their determinations by flame atomic 
absorption spectrometry, Toxicological \& Environmental Chemistry, 98(2), 179-188.

Baliza, P.X.,Teixeira L.S.G., ve Lemos.V. A., 2009. A procedure for determination of cobalt in water samples after dispersive liquid-liquid microextraction, Microchemical Journal, 93(2), 220-224.

Box, G.E.P., ve Behnken, D.W., 1960. Some new three level designs for the study of quantative variables, Technometrics, 2, 455-475.

Camel, V., 2003. Solid phaseextraction of trace elements, Spectrochimica Acta Part B: Atomic Spectroscopy, 58(7), 1177-1233.

Citak, D., ve Tuzen, M., 2010. A novel preconcentration procedure using cloud point extraction for determination of lead, cobalt and copper in water and food samples using flame atomic absorption spectrometry, Food and Chemical Toxicology, 48(5), 1399-1404.

Ferreira, S.L.C., ve De brito, C.F., 1999. Separation and preconcentration of cobalt after sorption onto Amberlite XAD-2 loaded with 2-(2-thiazolylazo)-p-cresol, AnalyticalSciences, 15(2), 189-191.

Hejazi, L.,Mohammadi, D.E., Yamini, Y., ve Brereton, R.G., 2004. Solid-phase extraction and simultaneous spectrophotometric determination of trace amounts of $\mathrm{Co}, \mathrm{Ni}$ and $\mathrm{Cu}$ using partial leasts quares regression, Talanta, 62(1), 183-189.

Jamali, M.R.,Soleimani, B., ve Rahnama, R., 2017. A novelseparation/preconcentration procedure using in situ sorbent formation microextraction for the determination of cobalt (II) in water and food samples by flame atomic absorption spectrometry, Arabian Journal of Chemistry, 10, 31503155 .

Khoddami, N., ve Shemirani, F., 2016. A new magneticion-imprintedpolymer as a highly selective sorbent for determination of cobalt in biological and environmental samples, Talanta, 146, 244-252.

Lemos, V.A., Gama, E.M., ve Da Silva Lima, A. 2006. On-linepreconcentration and determination of cadmium, cobalt and nickel in food samples by flame atomic absorption spectrometry using a new functionalized resin, Microchimica Acta, 153(3-4), 179186.

Lemos, V.A.,Santos, J.S., Nunes, L.S., De Carvalho, M.B., Baliza, P.X., ve Yamaki, R.T., 2003. Amberlite XAD-2 functionalized with Nitroso $\mathrm{R}$ salt: synthesis and application in an online system for preconcentration of cobalt, Analytica Chimica Acta, 494(1-2), 87-95.

Montgomery, D.C., 1991. Design and Analysis of Experiments, John Wiley Sons Inc., Singapore.

Safavi, A.,Iranpoor, N., Saghir, N., ve Momeni, S., 2006. Glycerol-silica gel: a new solid sorbent for preconcentration and determination of traces of cobalt (II) ion, Analytica Chimica Acta, 569(1), 139-144.

Sivrikaya, S.,Imamoglu, M., Yıldız, S.Z., ve Kara, D., 2016. Novel Functionalized Silica Gel for On-line Preconcentration of Cadmium (II), Copper (II) and Cobalt (II) with Determination by Flame Atomic Absorption Spectrometry, Analytical Letters, 49(7), 943-957.

Soylak, M., Karatepe, A.U., Elçi, L., ve Doğan, M., 2003. Column preconcentration / separation and atomic absorption spectrometric determinations of some heavy metals in table salt samples using amberlite XAD-1180, Turkish Journal of Chemistry, 27(2), 235-242.

Soylak, M., Kaya, B. ve Tuzen, M., 2007. Copper (II)-8-hydroxquinoline coprecipitation system for preconcentration and separation of cobalt (II) and manganese (II) in real samples, Journal of Hazardous Materials, 147(3). 832-837.

Teixeira Tarley, C.R., Fernandes, F.F., Luccas, P.O.,ve Segatelli, M.G., 2011. Enhanced Selectivity and Sensitivity for Flow Injection Spectrophotometric Determination of Cobalt Using Solid Phase Extraction with a 2D Ion-Imprinted Adsorbent, Analytical Letters, 44(1-3), 216-231.

Topuz, B., 2004. Potasyum 2.6-dimetilmorfolinditiyokarbamat sentezi ve bazı içeceklerde bakır ve kurşunun FAAS ile tayininde 
kullanılması,Yüksek lisans Tezi, Ondokuz Mayıs Üniversitesi Fen Bilimleri Enstitüsü, Samsun, 85s.

Topuz, B., ve Macit. M., 2011. Solid phase extraction and preconcentration of $\mathrm{Cu}$ (II), $\mathrm{Pb}$ (II) and $\mathrm{Ni}$ (II) in environmental samples on chemically modified Amberlite XAD-4 with a proper Schiffbase, Environmental Monitoring and Assessment, 173(1), 709722.
Wang, L., Zhou, J.B., Wang, X., Wang, Z.H., ve Zhao, R.S., 2016. Simultaneous determination of copper, cobalt and mercury ions in water samples by solidphase extraction using carbon nanotubesponges as adsorbent after chelating with sodiumdiethyldithiocarbamate prior to high performance liquid chromatography, Analytical and Bioanalytical Chemistry, 408 (16), 44454453. 